\title{
The Relationship between Start Speed, Acceleration and Speed Performances in Soccer
}

\author{
Suat Yıldız ${ }^{1, *}$, Osman Ateş ${ }^{2}$, Ertuğrul Gelen ${ }^{3}$, Erdem Çırak ${ }^{1}$, Doğuş Bakicı ${ }^{1}$, Volkan Sert ${ }^{4}$, \\ Gürhan Kayıhan ${ }^{5}$ \\ Faculty of Sport Sciences, Manisa Celal Bayar University, Turkey \\ ${ }^{2}$ Faculty of Sport Sciences, Istanbul University, Turkey \\ ${ }^{3}$ Faculty of Sport Sciences, Sakarya University, Turkey \\ ${ }^{4}$ Faculty of Sport Sciences, Van Yüzüncü Y1l University, Turkey \\ ${ }^{5}$ Oxford University Hospitals NHSP \& Chippenham Community Hospital Swindon, Oxford OX3 9DU, England
}

Copyright $\mathrm{O} 2018$ by authors, all rights reserved. Authors agree that this article remains permanently open access under the terms of the Creative Commons Attribution License 4.0 International License

\begin{abstract}
Start speed, acceleration, and speed performance are critical factors affecting directly football player's performance. The aim of our study was to examine the relationship among these three abilities. 79 football players voluntarily participated in the study (height: 177,96 $\pm 5,4 \mathrm{~cm}$; weight $73,72 \pm 7,85 \mathrm{~kg}$; training age: $10,59 \pm 2,94$ years; age: $21,90 \pm 2,66$ years). Participant's tests have been taken on non-consecutive days in RT (visual reaction test, Lafayette, Moart Reaction and Movement), Speed (Total 15m; Fusion Sport, Smart Speed), Start speed (0-5m; Fusion Sport, Smart Speed), and acceleration $(5-15 \mathrm{~m}$; Fusion Sport, Smart Speed). The first $5 \mathrm{~m}$ is start speed, $5-15 \mathrm{~m}$ is acceleration phase and total $15 \mathrm{~m}$ is speed. Significant correlation has been found between star speed and speed $(p<0,01)$; training age and start speed $(p<0,05)$; height and last $5 \mathrm{~m}$ performance. Otherwise, the adverse correlation has been found between the second $5 \mathrm{~m}$ and last $5 \mathrm{~m}$ performances $(p<0,01)$. There is no significant correlation between reaction time and $15 \mathrm{~m}$ speed performance $(p>0,05)$. There is significant correlation between acceleration and $15 \mathrm{~m}$ speed $(p<0,05)$, and between second $5 \mathrm{~m}(p<0,01)$ and third $5 \mathrm{~m}$ performances. The football players who have good rates of start speed times have good speed performance due to their physical capabilities. The rate of ground reaction forces is the most important factor that affects acceleration. Hence it's recommended that activities including Olympic weightlifting be performed to increase the rate of ground reaction forces.
\end{abstract}

Keywords Start Speed, Acceleration, Speed, Reaction Time, Football

\section{Introduction}

Soccer is the multiple sports that include the change of direction, acceleration, deceleration running back and forth $[1,2]$. Speed is one of the parameters that directly influence performance [3]. Speed can be described the ability to cover a distance accelerating from one point to another in high velocity as well as a product of the mathematical results of stride length and frequency [4]. Stride length, during consecutive steps distance between heels of same foot [5]. Stride frequency (rate), during a running number of steps of each foot [6]. Start, push off, acceleration and maximum velocity are phases of the speed [4]. A soccer player sprints in average between $110-330 \mathrm{~m}$ during a game with respect to playing the position [7].

Acceleration and deceleration describe velocity's change in the unit of time. Acceleration, change of rate of velocity [8]. Acceleration is the first $10 \mathrm{~m}$ of the sprint activity $[9,10]$. In this phase, start speed phase can be described as first $5 \mathrm{~m}$ [11]. In the $10 \mathrm{~m}$ stride frequency is high, stride length is short and there is maximum propulsion $[9,12,13]$. In other words, athlete tries to produce the maximum force in the minimal time [5]. This ability can be seen in the soccer-like any other sport $[7$, 14-17].

A soccer player covers $10-11 \mathrm{~km}$ in a game with respect to the position [7]. According to a study average distance of the sprint activity is $16.5 \mathrm{~m}$ [19]. In another study It's indicated that professional soccer player during a game sprints $\% 7 \pm 0.9$, between $0-10 \mathrm{~m} ; \% 48 \pm 16$, between $10-20 \mathrm{~m}, \% 45 \pm 17$ more than $20 \mathrm{~m}$ [20]. While performing speed activities start speed and acceleration abilities are important. While covering these distances ability to sprint is performed to change score of the competition [18]. It is very important to understand speed performance and driving elements of speed in football competition performance. Our study's purpose is to examine the relationship between start speed, acceleration and speed performances. 


\section{Materials and Methods}

79 soccer players who play actively voluntarily participated in the study (Height: 177,96 $\pm 5,4 \mathrm{~cm}$; Weight $73,72 \pm 7,85 \mathrm{~kg}$; Training Age: 10,59 $\pm 2,94$ Years; age: $21,90 \pm 2,66$ Years). Participants were informed before the test about testing procedures. A permission has been obtained from the ethics committee of the Manisa Celal Bayar University.

Tests of the participants were performed in the track of Manisa Celal Bayar University. Participants warmed up proper to recommendations of the Gelen [21] $15 \mathrm{~m}$ course's phase is first $5 \mathrm{~m}$ start speed, first $10 \mathrm{~m}$ acceleration and entire $15 \mathrm{~m}$ course speed (Figure 1).

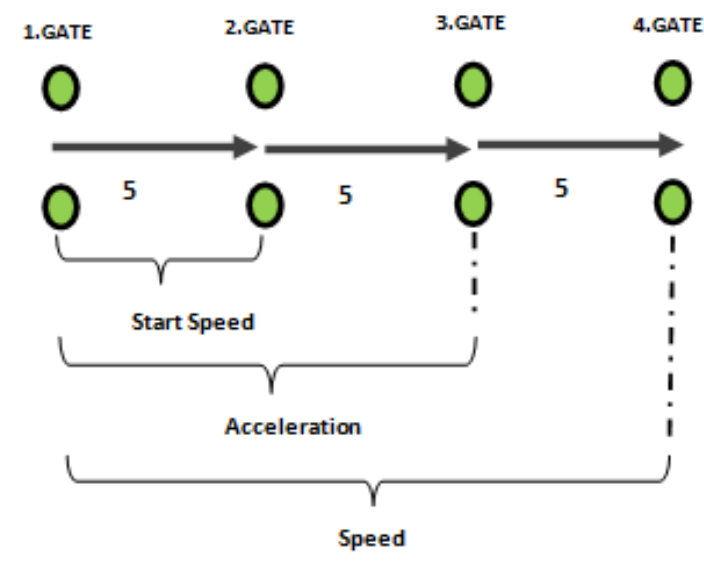

Figure 1. Testing of start speed, acceleration and speed

\subsection{Collection of Data}

The anthropometric measurements of participants included height lengths, body weights, age and training ages. Tests were taken in hours between $12.00 \mathrm{am}-14.00$ pm. In the 15-meter speed test, data were obtained with the mobile application of the Fusion Sport, Smart Speed device. In the visual reaction time test, data were obtained using the control panel of Lafayette, Moart Reaction, and Movement device.

\subsection{Meter Speed Test}

On the same day, the same tests were conducted on the same test track (Speed 15m, Fusion Sport, Smart Speed), Start Speed (Fusion Sport, Smart Speed) and Acceleration (0-10m; Fusion Sport, Smart Speed).

\subsection{Analysis of Data}

The obtained data were compared with the Pearson correlation analysis test and the mean values between the measurements were analyzed.

\section{Results}

On the same day, the same tests were conducted on the same test track (Speed 15m, Fusion Sport, Smart Speed), Start Speed (Fusion Sport, Smart Speed) and Acceleration (0-10m; Fusion Sport, Smart Speed). Very significant relationship was found between start speed and speed performance $(p<0.01)$; significant relationship between the second 5 meters and the last 5 meters $(p<0.05)$. A very significant relationship was found between the second $5 \mathrm{~m}$ and the last $5 \mathrm{~m}$, acceleration and speed ( $p$ $<0.01)$. a very significant relationship was found between last 5 meters, and acceleration and speed $(p<0.01)$. There is a significant relationship between acceleration and speed performance $(p<0.05$

Table 1. Participants' 0-5, 5-10 and 10-15m times

\begin{tabular}{|c|c|c|c|}
\hline & $0-5 \mathrm{~m}$ & $5-10 \mathrm{~m}$ & $10-15 \mathrm{~m}$ \\
\hline $\mathrm{N}$ & 78 & 73 & 73 \\
\hline Mean & 0,9513 & 0,7305 & 0,6786 \\
\hline Std. Deviation &, 07334 & ,06156 & ,05930 \\
\hline Minimum & ,79 &, 45 &, 56 \\
\hline Maximum & 1,20 & 1,01 & 1,04 \\
\hline
\end{tabular}

Table 2. Analysis of Relationship of Start Speed, Acceleration and Speed

\begin{tabular}{|c|c|c|c|c|c|c|}
\hline & & $0-5 \mathrm{~m}$ & $5-10 \mathrm{~m}$ & $10-15 \mathrm{~m}$ & $0-10 \mathrm{~m}$ & $15 \mathrm{~m}$ Speed \\
\hline \multirow{2}{*}{$0-5 \mathrm{~m}$} & r-value & 1 & ,281* &, $415^{* *}$ & ,137 &, $836^{* *}$ \\
\hline & p-value & &, 016 &, 000 &, 231 &, 000 \\
\hline \multirow{2}{*}{$5-10 \mathrm{~m}$} & r-value &, $281^{*}$ & 1 &,$- 305^{* *}$ &, $608^{* *}$ &, $462^{* *}$ \\
\hline & p-value &, 016 & &, 009 & ,000 &, 000 \\
\hline \multirow{2}{*}{$10-15 \mathrm{~m}$} & r-value &, $415^{* *}$ &,$- 305^{* *}$ & 1 &, $568^{* *}$ &, $541^{* *}$ \\
\hline & p-value &, 000 & ,009 & &, 000 & ,000 \\
\hline \multirow{2}{*}{$0-10 \mathrm{~m}$} & r-value & ,137 &, $608^{* *}$ &, $568^{* *}$ & 1 & ,280* \\
\hline & p-value &, 231 &, 000 & ,000 & & ,016 \\
\hline \multirow{2}{*}{$15 \mathrm{~m}$ Speed } & $r$-value &, $836^{* *}$ &, $462^{* * *}$ &, $541^{* *}$ &, $280^{*}$ & 1 \\
\hline & p-value &, 000 &, 000 &, 000 &, 016 & \\
\hline
\end{tabular}

*. Correlation is significant at the 0.05 level (2-tailed).

**. Correlation is significant at the 0.01 level (2-tailed). 


\section{Discussion}

Our study's purpose was to examine relationship between start speed, acceleration and speed performances. Start speed is an important component that affects soccer player's ability to perform soccer-specific offensive or defensive skills. Very significant relationship has been found between these two abilities $(p<0.01)$. Speed includes jumping [18]. Strength and conditioning coaches benefit from activities that require vertically force production [22]. While performing these activities athlete applies amount of force to the ground and then uses this produced force to throw the mass or transfers this force through other parts of the body. In this position athlete puts the body to the triple extension position and uses propulsive force of plantar flexors, knee and hip muscles. While performing start speed and acceleration phases athletes benefit from triple extension position further [12, 23]. In another study, significant relationship has been found between vertically produced force and $5 \mathrm{~m}$ start speed [11]. This result shows us that in start phase these groups of muscles contract concentrically to produce force and helps to carry the mass (body) to the forward. While ability of sprinting benefits from vertically force production as much as this, it would be beneficial for improving performance to add these movement patterns into the training programs. One of the important factors for the vertical force production is the range of motion (ROM) $[23,24]$. Another important factor which is mostly overlooked is force production of flexor Hallucis longus which is one of the toe flexors $[25,26]$. Due to sprinting activity includes jumping it will be beneficial to improve this muscle performance [24].

We described start speed as a section of acceleration phase. But we need to describe acceleration ability as a whole. Soccer player's ability to produce force during acceleration phase will make player's reaching maximal velocity earlier. This is acceptable in the soccer because sprinting distances are shorter than $30 \mathrm{~m}$ in the soccer [2]. The ability of acceleration benefits from the effect of hyperplasia which is the potential result of the maximal strength training. Hyperplasia is the increase in the number of muscle fibers during high-intensity activities [5]. Due to this concern, it's special ability for the soccer players. In the study which has been done between soccer players showed that increase in maximal squat result with the improvement of the short distance sprinting performance [27]. After the maximal strength training, power training that we aim to improve the speed of the movement shouldn't be neglected [28]. While making up training programs, exercises which improve stretch-shortening cycle should be added as well. In the stretch-shortening cycle lower body extensor muscles contracts quickly and eccentrically to create a resistance after this point sudden and concentric contraction follows to create new movement [29]. If this occurs in the short time, hence it's assumed that performance will improve.

\section{Conclusions}

In conclusion, the ability of start speed, acceleration and speed are affected by various factors. To gain the capabilities of the athletes, exercises that require vertical force production such as, Olympic weightlifting and essential movement pattern including exercises squat, deadlift, improving ankle ROM and plyometric exercises which will shorten the time of stretch-shortening cycle should be added to the training programs.

\section{REFERENCES}

[1] Jeffreys, I., Movement Training for Field Sports: Soccer. Vol. 30. 2008. 19-27.

[2] Stolen, T., et al., Physiology of soccer: an update. Sports Med, 2005. 35(6): p. 501-36.

[3] Haugen, T., et al., The role and development of sprinting speed in soccer. Int J Sports Physiol Perform, 2014. 9(3): p. 432-41.

[4] Struzik, A., et al., Relationship between lower limbs kinematic variables and effectiveness of sprint during maximum velocity phase. Acta Bioeng Biomech, 2015. 17(4): p. 131-8.

[5] Haff, G.G. and N.T. Triplett, Essentials of Strength Training and Conditioning 4th Edition. 2015: Human Kinetics Publishers.

[6] Hoffman, J., Physiological Aspects of Sport Training and Performance-2nd Edition. 2014: Human Kinetics.

[7] Dalen, T., et al., Player Load, Acceleration, and Deceleration during Forty-Five Competitive Matches of Elite Soccer. J Strength Cond Res, 2016. 30(2): p. 351-9.

[8] Brown, L.E. and V. Ferrigno, Training for Speed, Agility, and Quickness. 2005: Human Kinetics.

[9] Hewit, J., et al., Understanding Deceleration in Sport. Vol. 33. 2011. 47-52.

[10] Little, T. and A.G. Williams, Specificity of acceleration, maximum speed, and agility in professional soccer players. J Strength Cond Res, 2005. 19(1): p. 76-8.

[11] Sleivert, G. and M. Taingahue, The relationship between maximal jump-squat power and sprint acceleration in athletes. Eur J Appl Physiol, 2004. 91(1): p. 46-52.

[12] Joyce, D. and D. Lewindon, High-Performance Training for Sports. 2014: Human Kinetics Publishers.

[13] Kawamori, N., K. Nosaka, and R.U. Newton, Relationships between ground reaction impulse and sprint acceleration performance in team sport athletes. J Strength Cond Res, 2013. 27(3): p. 568-73.

[14] Ingebrigtsen, J., et al., Acceleration and sprint profiles of a professional elite football team in match play. Eur J Sport Sci, 2015. 15(2): p. 101-10. 
[15] Mara, J.K., et al., The acceleration and deceleration profiles of elite female soccer players during competitive matches. J Sci Med Sport, 2017. 20(9): p. 867-872.

[16] Ryan, M., S. Malone, and K. Collins, Acceleration Profile of Elite Gaelic Football Match Play. J Strength Cond Res, 2018. 32(3): p. 812-820.

[17] Varley, M.C., T. Gabbett, and R.J. Aughey, Activity profiles of professional soccer, rugby league and Australian football match play. J Sports Sci, 2014. 32(20): p. 1858-1866.

[18] Moir, G., Biomechanics of Fundamental Movements: Sprint Running. 2015. 523-574.

[19] Carling, C., F. Le Gall, and G. Dupont, Analysis of repeated high-intensity running performance in professional soccer. J Sports Sci, 2012. 30(4): p. 325-36.

[20] Andrzejewski, M., et al., Analysis of sprinting activities of professional soccer players. J Strength Cond Res, 2013. 27(8): p. 2134-40.

[21] Gelen, E., Acute effects of different warm-up methods on sprint, slalom dribbling, and penalty kick performance in soccer players. J Strength Cond Res, 2010. 24(4): p. 950-6.

[22] Loturco, I., et al., Improving Sprint Performance in Soccer:
Effectiveness of Jump Squat and Olympic Push Press Exercises. PLOS ONE, 2016. 11(4): p. e0153958.

[23] Yildiz, S. and E. Gelen. An Examination of The Relationship Between Ankle Mobility and Jump Height in Tennis Athletes, in World Congress of Sport Sciences Researches. 2017: Manisa/Turkey.

[24] Yun, S.J., et al., Correlation between toe flexor strength and ankle dorsiflexion ROM during the countermovement jump. J Phys Ther Sci, 2016. 28(8): p. 2241-4.

[25] Goldmann, J.P., et al., The potential of toe flexor muscles to enhance performance. J Sports Sci, 2013. 31(4): p. 424-33.

[26] Péter, A., et al., Function of the flexor hallucis longus muscle - what do we know? Vol. 17. 2016. 46-50.

[27] Styles, W.J., M.J. Matthews, and P. Comfort, Effects of Strength Training on Squat and Sprint Performance in Soccer Players. J Strength Cond Res, 2016. 30(6): p. 1534-9.

[28] Clark, M., et al., NASM Essentials of Personal Fitness Training. 2012: Wolters Kluwer Health/Lippincott Williams \& Wilkins.

[29] Herzog, W., Biomechanics in Sport: Performance Enhancement and Injury Prevention. 2008. 21-32. 